\title{
Mediation of employee job satisfaction on the relationship between internal corporate social responsi-
} bility and affective commitment

\author{
Trang Thi Tran ${ }^{a}$, Tien Thuy Nguyen ${ }^{b}$, Duyen Nguyen Thien Ngo ${ }^{b}$ and Tung Anh $\operatorname{Tran}^{\mathrm{b} *}$
}

${ }^{a}$ Ho Chi Minh City University of Technology (HUTECH), Vietnam

${ }^{b}$ Hong Bang International University, Vietnam

\section{H R O N I C L E}

\section{Article history:}

Received: June 27, 2020

Received in revised format:

August 102020

Accepted: August 10, 2020

Available online:

August 10, 2020

Keywords:

CSR

Job satisfaction

Affective Commitment

\section{A B S T R A C T}

This paper proposes a quantitative approach with statistical techniques for identifying the relationship between Internal Corporate Social Responsibility (ICSR) and Affective Commitment (AC) and clarifying the mediating effects of job satisfaction of employee. Five factors of ICSR including human rights, training and education, health and safety, work-life balance, and workplace diversity were examined. The major method in this paper is based on the quantitative approach, in which statistical techniques including Factor Analysis, Multiple Regression, and Path Analyses were performed. The unit of analysis was at individual level with the sample size of 233 employees who are working in different departments. The findings of this study showed that the higher levels of human rights, health and safety, job satisfaction and work-life balance employees were perceived at the higher level of AC. Based on the results of the path analysis, this study argued that to achieve high employee AC, employers should reach higher level of employee job satisfaction and improve human rights, health and safety and work-life balance. Although there were limitations, this study is expected to highlight several implications for small and medium companies in building ICSR.

C 2021 by the authors; licensee Growing Science, Canada

\section{Introduction}

In recent years, ICSR has become an important strategy of organizational competences. Primary studies have shown that employees, who are committed to organization, might work harder, and contribute much more to the company. In addition, many studies pointed out that job satisfaction of the employees can affect the decision of changing job or quitting job altogether (Chew \& Chan, 2008; Heller, Perunovic, \& Reichman, 2009; Shahnawaz \& Jafri, 2009). It is obvious that practices of the physical and psychological working environment of employees are ICSR such as social responsibility for instances human rights, training and education, health and safety, work-life balance, workplace diversity are involved. This research investigated the application of ICSR on the real case of pharmacy industry based on the condition of ICSR such as human rights, training and education, health and safety, work-life balance, workplace diversity. As a result, through the survey results, the study indicated whether ICSR had a real effect on employee commitment through the mediating role of job satisfaction.

\section{Literature review}

\subsection{Internal Corporate Social Responsibility}

ICSR is the action of firm to satisfy the expectation of workers and employees including training and education; health and safety; human rights; work-family balance, and workplace diversity (Ehnert, Harry, and Zink, 2014).

\subsubsection{Training and Education}

According to Buckley and Caple (2009), training is "a planned and systematic effort to modify or develop knowledge/skill/attitude through learning experience to achieve effective performance." Whilst education is "a process and a series of activities

* Corresponding author.

E-mail address: tungta@hiu.vn (T. A. Tran) 
which aim at enabling an individual to assimilate and develop knowledge, skills, values and understanding that allows a broad range of problems to be defined, analyzed and solved."

\subsubsection{Health and Safety}

Health and safety are "concerned with preserving and protecting human and facility resources in the workplace." (Friend \& Kohn, 2010). In addition, since health and safety concern with improving organizational quality and efficiency, so company should provide health and safety work environment which can be psychosocial and physical. In particular, the psychosocial work environment is related to employee's integrity and dignity; how organization enables open communication with other employees; how employees feel safe understood as no harassment or other improper conduct. While on the other hand, the physical one can be problems of building and equipment, climate, lighting, noise, and radiation.

\subsubsection{Human Rights}

According to United Nations Human Rights, human rights are "rights inherent to all human being, regardless nationality, place if residence, sex, ethnic origin, religion, language, or any other status". In line with this, the practices of Human Rights at work regarding to the protection from discrimination covers all stages of an employment relationship including employment, employment conditions, promotions and dismissal or termination of employment (Hilgert, 2012).

\subsubsection{Work-life Balance}

Work-life balance refers to enabling the employees to allocate time and energy for both work and other important aspects of their lives such as family, friends, community, personal growth, self-care, and spirituality (Heathfield, 2007). Firms can enhance work-life balance with ideas such as job sharing, flexible work schedules, paid time off policies (e.g. sick days, vacation days, and personal days) and company sponsored family events and activities.

\subsubsection{Workplace Diversity}

According to Chartered Institute of Personnel Development, workplace diversity is the combination of visible and non-visible factors such as sex, race, age, background, culture, disability, personality, and work style. When companies recognize value diversity, it will enhance individual productivity, organizational effectiveness, and sustained competitiveness (Konrad, 2005; Patrick and Kumar, 2012; Stockdale, 2004).

\subsection{Employee job satisfaction}

Based on the foundation of Hawthorne effect founded by Landsberger (1958), with the concept of employee job satisfaction, employees were considered working for other purpose than payment. The definition of job satisfaction very well-known was developed by Locke, in which the job satisfaction was "a pleasure or positive emotional state resulting from the appraisal of one's job or job experience". In addition, in Lund (2003), the job satisfaction was measured and defined both as multiple aspects or dimensions with a level of global construct. Therefore, from those previous studies, the employee job satisfaction must be examined through various factors.

\subsection{Affective commitment}

Commitment includes three types: affective, continuance, and normative commitment (Allen \& Meyer, 1990). Affective commitment (AC) is defined as "positive feelings of identification, attachment and involvement in the work organization". Continuance commitment refers to "the extent which employee feels committed to their organization by virtue of the costs that they feel are associated with leaving." Meanwhile, normative commitment reflects the feeling of employee in dealing with obligation to remain with the organization. This study only focused on AC since this dimension is arguably the most desirable form of commitment and the one that organizations are most likely to want to instill in their employees.

\subsection{Linkages among ICSR, Job Satisfaction and AC}

There are numerous studies related to the relationship between CSR and Job Satisfaction, between ICSR and Employee Commitment and between Job Satisfaction and Job commitment. Rettab, Brik and Mellahi (2009) conducted a research to examine the link between ICSR activities and three measures of organizational performance: financial performance, employee commitment, and corporate reputation in emerging economies, United Arab Emirates. The results show that CSR has a positive relationship with employee commitment. the perception of CSR, job satisfaction, personality was related to organizational commitment was found, in which there were the existence effects of external CSR and ICSR on organizational commitment, (Lee \& Bruvold, 2003, Brammer et al., 2007). Job satisfaction had not only been considered as the strongest predictors of turnover intent, but also a correlate of organizational commitment (Meyer et al., 2002). Both organizational commitment and 
job satisfaction can be influenced by the climate prevalent in the organization. Therefore, employee perceptions of the organization's CSR initiatives are likely to affect their evaluation of the organizational climate and the relationship between ethical climate in an organization, job satisfaction and organizational commitment was tested (Tsai and Huang, 2008). However, the extant literature shows very few studies which examine the relationship between ICSR and AC through the mediation of job satisfaction, especially in the pharmaceutical industry. Based on the mentioned literature review, we developed the following hypotheses and a conceptual research model for our research.

\section{Hypotheses}

$\checkmark \quad \mathrm{H}_{1}$ : Factors of ICSR (training and education, health and safety, human rights, work-life balance and workplace diversity) positively affect employee job satisfaction.

$\checkmark \quad \mathrm{H}_{2}$ : AC is indirectly affected by factors of ICSR (training and education, health and safety, human rights, work-life balance and workplace diversity) through job satisfaction.

\section{Conceptual research model}

From the two hypotheses $\mathrm{H}_{1}$ and $\mathrm{H}_{2}$ with ICSR, a conceptual research model is proposed to clarifying the mediating effects of job satisfaction of employee as shown in Fig. 1.

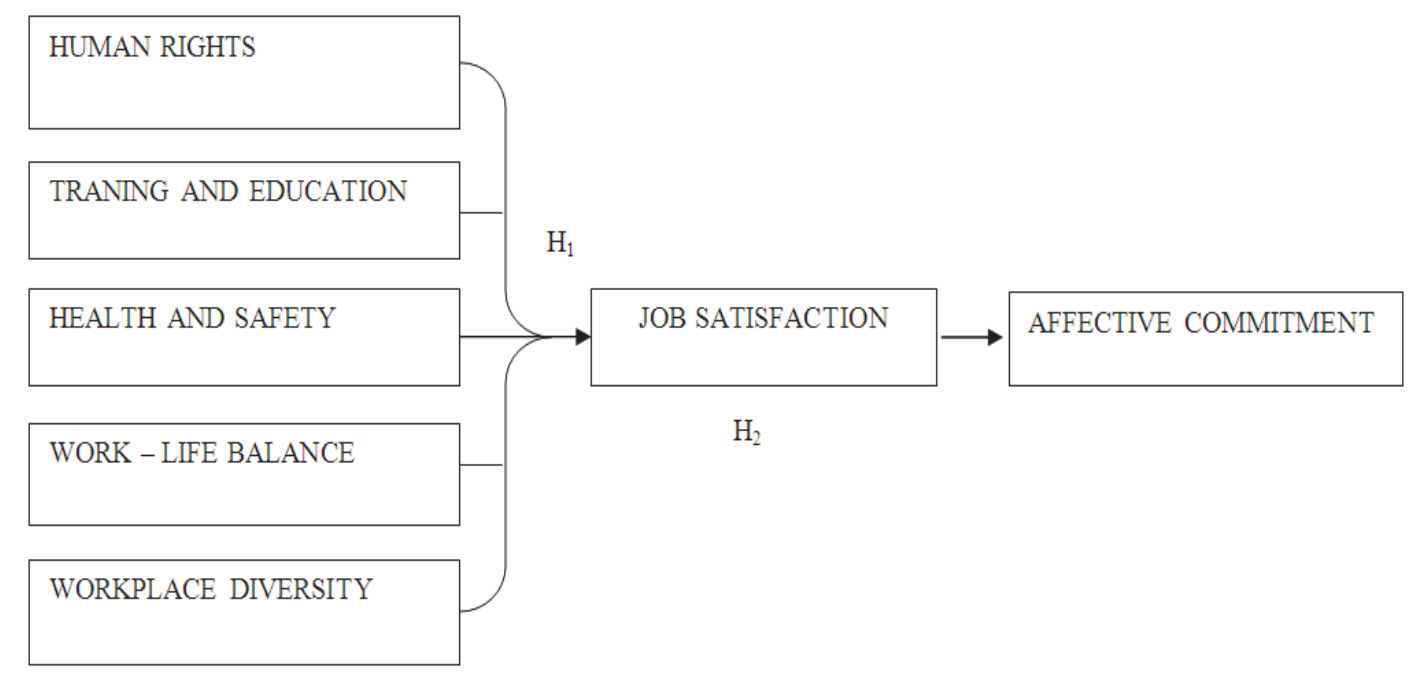

Fig. 1. Conceptual research model

\section{Methodology}

The designed questionnaire was directly and conveniently sent to 233 respondents who are direct employees working in factories and indirect employees working in offices. Therefore, in Exploration Factors Analysis (EFA), according to Gorsuch (1983), a minimum subject-to-variables ratio should not be lower than 5:1. In addition, when this ratio is acceptable, and noticed that higher ratios are generally better as well. Based on the research model of this study, the number of items used to measure were dependent variables of AC (4 items) and Employee Job Satisfaction (4 items) and independent variables of Human Rights (6 items), Training and Education (5 items), Health and Safety (5 items), Work-life Balance (4 items), and Workplace Diversity (5 items). Hence, the ratio applied for EFA of dependent variables was 29:1 and the ratio for EFA of independent variables was 9:1. Statistically, these ratios promise a better reliability and validity of variables of this study.

Based on the aforesaid literature review and the proposed conceptual research model, the questionnaire was designed in accordance with measured variables of five independent variables and two dependent variables. In this study, the five-point Likert scale, ranging from 1 is "strongly disagreed" to 5 is "strongly agreed", was used in the questionnaire for the survey and most of questions were set as statements. The hard copy of questionnaire with directions and detailed contents was sent directly to respondents working in Pharmaceutical industry and the answers of respondents were collected within one week.

Two exploratory factory analyses which used the principal component extraction method and Varimax rotation of 8 items of the dependent variables of AC and employee job satisfaction and 25 items of the independent variables of ICSR to employees were applied to analyze with SPSS software. Before inputting the data into the SPSS software, these data were tested by examining the descriptive statistics on each item, inter-item correlations, and possible univariate and multivariate assumption violations. From this preliminary assessment, all variables were found to be continuous, variable pairs appeared to be bivariate 
normally distributed, and all cases were independent on one another. For this study, the Exploratory Factor Analysis (EFA) procedure was applied twice; once for the dependent variables and again for the group of five independent variables. The Kaiser-Meyer-Olkin measure of sampling adequacy was .841 for the dependent variables and .838 for the independent variables (according to Pallant, 2005, to be significant, the value has to be .60 or above), indicating that the present data was suitable for principal components analysis. In similarity, Bartlett's test of sphericity was significant $(p<.001)$, indicating sufficient correlation between the variables to proceed with the analysis. Using the Kaiser-Guttman's retention criterion of Eigenvalues greater than 1.0, a two-factor solution provided the clearest extraction for the dependent variables, including 8 items. The two factors of the dependent variables accounted for $64 \%$ of the total variance and the Cronbach's coefficients ranged from .791 to .818 , indicating good reliability.

Table 1

Summary of Dependent Variables with Reliability Coefficients

\begin{tabular}{lcc}
\multicolumn{1}{c}{ Factors } & Number of Items & Cronbach's Alpha (N=233) \\
\hline Factor 1: Employee AC(JOCOM) & 4 & .818 \\
Factor 2: Employee Job Satisfaction (JOSA) & 4 & .791 \\
\hline
\end{tabular}

For the group of independent variables, factors were extracted which respectively corresponded to the concepts of Human Rights, Training and Education, Health and Safety, Work-life Balance, and Workplace Diversity of the research model. All items of ICSR were loading below the cut point of .50 so researcher decided to exclude these low loading items. The Eigenvalues of five extracted factors were greater than one and together, these five factors accounted for almost $61 \%$ of the variability in the original variables satisfying the requirement of being greater than $50 \%$. Moreover, each factor generated from the exploratory analysis had the high value of Cronbach's Alpha (ranging from .806 to .849), which implied the high reliability of the measurement scale for assessing the independent variables.

Table 2

Summary of Independent Variables with Reliability Coefficients

\begin{tabular}{lcc}
\hline Factors & Number of Items & Cronbach's Alpha (N= 233) \\
\hline Factor 1: Human Rights (HR) & 6 & .849 \\
Factor 2: Training and Education (TE) & 5 & .843 \\
Factor 3: Health and Safety (HS) & 5 & .817 \\
Factor 4: Work-life Balance (WB) & 4 & .834 \\
Factor 5: Workplace Diversity (WD) & .806 \\
\hline
\end{tabular}

\section{Research findings}

In factors affecting employee affective commitment, the main purpose of this research is figured out the effects of ICSR on $\mathrm{AC}$, through the moderated variable employee job satisfaction. In order to test the hypothesis (H1, H2), the two multiple regression analyses were processed. Firstly, the first regression result was able to test the effect between the independent variables and to identify which factors significantly influence and predict employee job satisfaction. Secondly, the next hypothesis was conducted to test the effect of the independent variables and employee job commitment on the moderated variable employee job satisfaction.

\section{Correlations between variables}

As the result observed from table 3, there were significant relationships between independent variables: HR, TE, HS, WB, and dependent variable JOSA. In these significant relationships, JOSA and HS are indicated strongly positive correlation (r $=.549, \mathrm{p}<0.05)$. It means that the higher Health and Safety for employees is the higher level of job satisfaction employees feels. In addition, the variables of WB, TE and HR were strongly correlated with JOSA $(r=.488, p<0.05),(r=.377, p<0.05)$ and $(\mathrm{r}=.351, \mathrm{p}<0.05)$, respectively. This means that, the better of work-life balance, training and education, and human right in ICSR, would lead to the higher job satisfaction of employees. Nevertheless, WD has shown the insignificant relationship with job satisfaction $(\mathrm{p}=0.113>0.05)$. The results of correlation coefficient in Table 3 also indicate significant relationship between the moderated variable, JOCOM, and the independent variables: HR, TE, HS, and WB. In these significant relationships, there was a very strong positive correlation between HR and JOCOM $(\mathrm{r}=.549, \mathrm{p}<0.05)$. It means that the higher Human Right for employees, the higher level of AC employees does. Additionally, the variables of HS, TE and WB were strongly correlated with JOCOM $(r=.535, \mathrm{p}<0.05),(\mathrm{r}=.389, \mathrm{p}<0.05)$ and $(\mathrm{r}=.359, \mathrm{p}<0.05)$, respectively. This means that, the better of health and safety, training and education, and work-life balance, would lead to the higher AC of employees. Nevertheless, WD has shown the insignificant relationship with AC $(\mathrm{p}=0.137>0.05)$.

In conclusion, there were four out of five independent variables of this research had positively strong and significant relationship with employee's job satisfaction and employees job commitment. Those variables are Human Right, Health and Safety, Training and Education, and Work-life Balance. As a result, the table showed that the higher level in those variables was 
associated with the higher level in employee job satisfaction and commitment, and the variable Workplace Diversity would be considered as inappropriate variable in this situation to build up a regression model for employee job satisfaction and AC.

Table 3

The correlation between Independent Variables and Dependent Variables

\begin{tabular}{|c|c|c|c|c|c|c|c|c|}
\hline & & HR & $\mathrm{TE}$ & HS & WB & JOSA & JOCOM & WD \\
\hline \multirow{3}{*}{ HR } & Pearson Correlation & 1 & $.342^{* * *}$ & $.402^{* * *}$ & $.311^{* *}$ & $.351^{* *}$ & $.549^{* *}$ & .090 \\
\hline & Sig. (2-tailed) & & .000 & .000 & .000 & .000 & .000 & .171 \\
\hline & $\mathrm{N}$ & 233 & 233 & 233 & 233 & 233 & 233 & 233 \\
\hline \multirow{3}{*}{$\mathrm{TE}$} & Pearson Correlation & $.342^{* *}$ & 1 & $.382^{* *}$ & $.461^{* *}$ & $.377^{* *}$ & $.389^{* *}$ & .116 \\
\hline & Sig. (2-tailed) & .000 & & .000 & .000 & .000 & .000 & .078 \\
\hline & $\mathrm{N}$ & 233 & 233 & 233 & 233 & 233 & 233 & 233 \\
\hline \multirow{3}{*}{ HS } & Pearson Correlation & $.402^{* *}$ & $.382^{* *}$ & 1 & $.328^{* *}$ & $.549^{* *}$ & $.535^{* *}$ & .118 \\
\hline & Sig. (2-tailed) & .000 & .000 & & .000 & .000 & .000 & .071 \\
\hline & $\mathrm{N}$ & 233 & 233 & 233 & 233 & 233 & 233 & 233 \\
\hline \multirow{3}{*}{ WB } & Pearson Correlation & $.311^{* *}$ & $.461^{* *}$ & $.328^{* *}$ & 1 & $.488^{* * *}$ & $.359^{* *}$ & .063 \\
\hline & Sig. (2-tailed) & .000 & .000 & .000 & & .000 & .000 & .335 \\
\hline & $\mathrm{N}$ & 233 & 233 & 233 & 233 & 233 & 233 & 233 \\
\hline \multirow{3}{*}{ JOSA } & Pearson Correlation & $.351^{* *}$ & $.377^{* *}$ & $.549^{* *}$ & $.488^{* *}$ & 1 & $.454^{* *}$ & .104 \\
\hline & Sig. (2-tailed) & .000 & .000 & .000 & .000 & & .000 & .113 \\
\hline & $\mathrm{N}$ & 233 & 233 & 233 & 233 & 233 & 233 & 233 \\
\hline \multirow{3}{*}{ JOCOM } & Pearson Correlation & $.549^{* *}$ & $.389^{* *}$ & $.535^{* *}$ & $.359^{* *}$ & $.454^{* *}$ & 1 & .098 \\
\hline & Sig. (2-tailed) & .000 & .000 & .000 & .000 & .000 & & .137 \\
\hline & $\mathrm{N}$ & 233 & 233 & 233 & 233 & 233 & 233 & 233 \\
\hline \multirow{3}{*}{ WD } & Pearson Correlation & .090 & .116 & .118 & .063 & .104 & .098 & 1 \\
\hline & Sig. (2-tailed) & .171 & .078 & .071 & .335 & .113 & .137 & \\
\hline & $\mathrm{N}$ & 233 & 233 & 233 & 233 & 233 & 233 & 233 \\
\hline
\end{tabular}

**. Correlation is significant at the 0.01 level (2-tailed).

\section{Direct effects of ICSR on employee job satisfaction and commitment}

The indicators of coefficient and significant, as showed as table 4, implied that there were two out of four independent variables of this research had direct effect on employee job satisfaction. Those are Health and Safety, Work-Life Balance. Besides, in order to identify which factor had most influence to job satisfaction of employee, this study based on the standardized coefficient (Beta). Through that Health and Safety possessed the highest Beta with $(.395, \mathrm{p}<0.1)$, followed by Work-Life Balance with $(.308, \mathrm{p}<0.1)$.

Table 4

Effect Coefficients between Independent Variables and JOSA.

\begin{tabular}{|c|c|c|c|}
\hline Variables & standardized Coefficients & t-value & Sig. \\
\hline 1. HR & .077 & 1.336 & .183 \\
\hline 2. TE & .580 & .962 & .337 \\
\hline 3. HS & .395 & 6.779 & .000 \\
\hline 4. WB & .308 & 5.246 & .000 \\
\hline
\end{tabular}

Note: Dependent Variable: JOSA: Employee Job Satisfaction; Predictors: HR, TE, HS, WB; ANOVA: F = 40.469, Sig. =000, p < 0.1; Model summary: R²= .415

From the result of coefficients shown in Table 5, it can be seen that three of five independent variables of this research indicated positive effects on $\mathrm{AC}$, in which they are Human Rights $(\beta=.346, \mathrm{p}<0.1)$, Health and Safety $(\beta=.276, \mathrm{p}<0.1)$, Job Satisfaction $(\beta=.116, \mathrm{p}<0.1)$.

Table 5

Effect Coefficients between Independent Variables and JOCOM

\begin{tabular}{|c|c|c|c|}
\hline Variables & standardized Coefficients & t-value & Sig. \\
\hline 1. HR & .346 & 6.193 & .000 \\
\hline 2. TE & .093 & 1.584 & .115 \\
\hline 3. HS & .276 & 4.448 & .000 \\
\hline 4. WB & .062 & 1.024 & .307 \\
\hline 5. JOSA & .116 & 1.796 & .074 \\
\hline
\end{tabular}

\section{Indirect effects of ICSR on Affective Commitment}

The result of multiple regression analysis showed that the employee job satisfaction was mainly affected by two important factors: Work-Life Balance $(\beta=.046)$, and Health and Safety $(\beta=.2036)$. These two factors directly affected the intervening 
variable of employee job satisfaction and then employee job satisfaction directly caused an effect on AC $(\beta=.116)$. Therefore, through the intervening variable of employee job satisfaction, the factors of Work-Life Balance, and Health and Safety created indirect effects on $\mathrm{AC}$ at $(\beta=.036)$, and $(.046)$ respectively. These findings indicated that the factors of Work- Life Balance, and Health and Safety had significant positive effects on both employee job satisfaction and AC. Thus this study argues that when employees who feel that they are satisfied to the factors such as: Work- Life Balance, and Health and Safety, there are more likely to see that they are also more satisfied and committed to their current job.

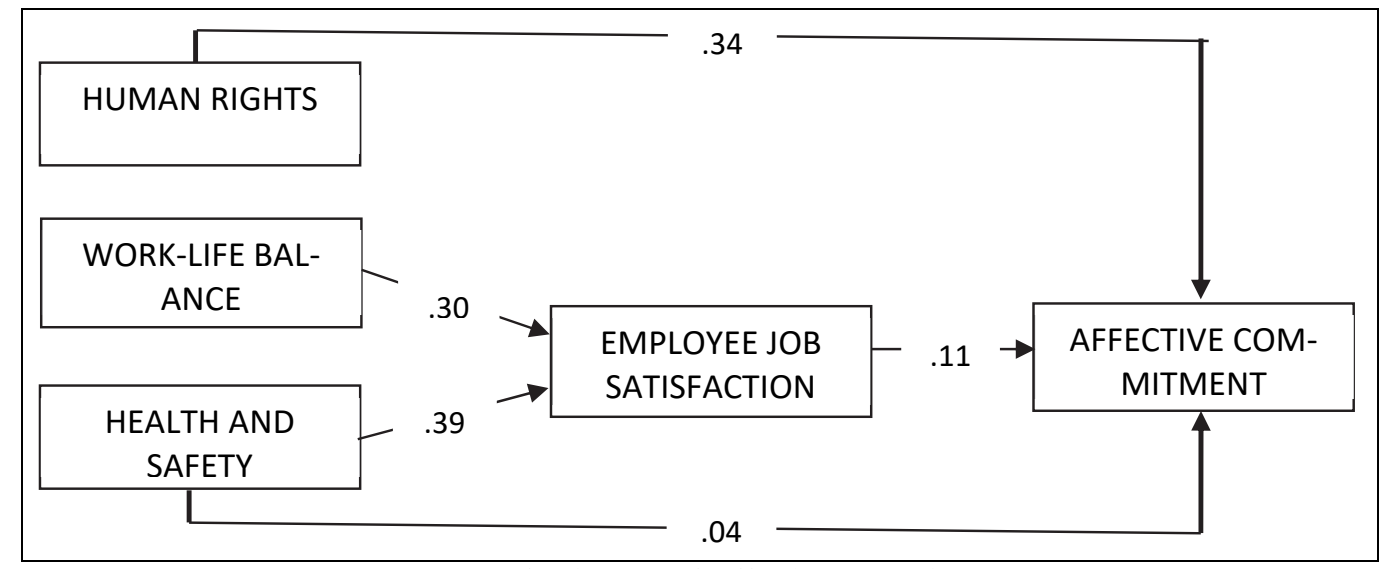

Fig. 2. Path Diagram of Affective Commitment

Total Causal Effects on Affective Commitment

Regarding the total effects, as showed in Table 6 , the Human Right had the strongest effect on Employee AC ( $\beta=.346$ ), Health and Safety $(\beta=.332)$, Job Satisfaction $(\beta=.116)$ and Work-Life Balance $(\beta=.036)$. Therefore, the total effect of these factors on employee $\mathrm{AC}$ was $\beta=.82$.

Table 6

Direct, Indirect, and Total Causal Effects

\begin{tabular}{|c|c|c|c|}
\hline \multirow{2}{*}{ Variables } & \multicolumn{3}{|c|}{ Causal effects } \\
\hline & Direct & Indirect & Total \\
\hline 1.HR & .346 & -- & .346 \\
\hline 2. TE & --- & --- & --- \\
\hline 3. HS & .276 & .046 & .322 \\
\hline 4. WB & --- & .036 & .036 \\
\hline 5. JOSA & .116 & --- & .116 \\
\hline Total & .738 & .082 & .820 \\
\hline
\end{tabular}

Based on the indicators observed in Table 6, this study can imply that Human Rights is the most important factor that affected to commitment of employees who are working in pharmaceutical industry, followed by Health and Safety, Job Satisfaction, and Work-Life Balance. Otherwise, the result of this study indicated that employees in the estimated Human Rights is the most important and crucial in order to keep strong commitment with their job related to the characteristic of ICSR such as Health and Safety, Work-Life Balance, and other components of Job Satisfaction.

\section{Discussion}

The study has presented empirical evidence related to the factors impacting AC directly and indirectly, as well as provided reliable scales to measure theoretical dimensions such as AC, job satisfaction, human rights, health and safety, and work-life balance. In addition, this study basically measured AC through employee job satisfaction. Based on the findings, the data showed in Table 4 indicated the effect coefficients between independent variables and employee job satisfaction. To be more precise, there are two significant variables $(\mathrm{p}<0.1)$ namely health and safety as well as work-life balance. Meanwhile, looking at the statistics in Table 5 exhibited the effect coefficients between independent variables and AC, there are three significant variables $(\mathrm{p}<0.1)$, including human rights, health and safety, and job satisfaction. The results from analyzing data indicate that ICSR in terms of human rights issue has the most positive and significant effect on AC of employees who are working in the pharmaceutical industry. This means that employees who perceive that their company is treating them fairly through employment policies. This faith strongly affects employee identification and involvement with their company, as well as enjoyment in being members of the organization. Peterson and Anand (2004) reported that "organizational performance in the ethical domain may have the greatest impact on organizational commitment because employees assume that if their company is ethical, the company will also treat them in an ethical manner. Conversely, companies that are not perceived as ethical might also be viewed as unlikely to treat their employees ethically resulting in a low level of organizational commitment". This was followed by the importance of maintaining a healthy and safe working environment for predicting employee's AC. In other words, if employees who perceived the work environment to be adequate Safe and healthy, then they will feel valued 
and can work more satisfied. This leads to positive attitudes toward various job components, which ultimately results in higher AC. Sutherland and Cooper (1990) argue that organizations should invest more resources in ensuring that the work environment is pleasant to and manageable by employees. By ensuring that equipment is functioning correctly and that there is adequate workspace, employees will feel more secure and settled in their surroundings and will become more committed to the organization. Furthermore, the results of this study present that work-life balance has a positive and significant relationship with AC. It means that higher levels of work-life balance initiatives are more likely to display higher levels of AC. For instance, when employees who perceived that their company are providing several initiatives which are beyond legal requirements such as maternity leave, other special leaves, flexible work schedules, and childcare facilities, that would help them to balance between home and work responsibilities, could lead to high AC. Rhoades \& Eisenberger (2002) argues that employee who experienced difficulties integrating their work and family roles will feel their organizations as unsupportive, therefore not perceive obligated to reciprocate with commitment. Hence, the organization needs to offer some supports which enabled them to balance their work and family responsibilities, assisted them overcome the difficult time in their life.

The present findings indicate that job satisfaction has significant positive relationships with AC. As a matter of fact, the higher levels of employee job satisfaction, the higher rates of AC amongst them. In other word, when employees feel more valued and more satisfied in their works, and as a result repaying the company with high AC. In contrast, regarding the result presented in both table 4 and table 5 , training and education dimension has the significant result $(\beta=0.58$ in the table 4 and $\beta=$ 0.093 in the table 5 , given $\mathrm{p}>0.1$ ). Consequently, there are not enough evidence to prove the relationship between training and education and AC in this study. Therefore, training and education is eliminated from the model for multiple-linear regression as well as the finally revised model.

\section{Conclusion}

This paper has represented the factors with the empirical evidence which impacted AC directly and indirectly and also provided reliable scales for measuring theoretical dimensions such as AC, job satisfaction, human rights, health and safety, and work-life balance, in which measuring $\mathrm{AC}$ was performed through employee job satisfaction. In addition, two significant variables $(\mathrm{p}<0.1)$ namely health and safety as well as work-life balance and three significant variables $(\mathrm{p}<0.1)$, including human rights, health and safety, and job satisfaction were used for more precise. The results from analyzing data indicate that ICSR in terms of human rights issue has the most positive and significant effect on AC of employees who are working in the pharmaceutical industry. To sum up, this study theoretically has contributed in building a more comprehensive research model for measuring $\mathrm{AC}$ directly and indirectly through the mediation of job satisfaction, and providing a better understanding of the causal relationships between factors of human rights, health and safety, work-life balance, employee job satisfaction, and $\mathrm{AC}$; thereby contributing to the existing diversified literature in the field of organization management.

\section{References}

Albdour, A. A., \& Altarawneh, I. I. (2012). Corporate social responsibility and employee engagement in Jordan. International Journal of Business and Management, 7(16), 89.

Ali, A., Nasruddin, E., \& Lin, S. K. (2010). The relationship between internal corporate social responsibility and organizational commitment within the banking sector in Jordan. International Journal of Economics and Management Engineering, 4(7), 1842-1861.

Allen, N. J., \& Meyer, J. P. (1990). The measurement and antecedents of affective, continuance and normative commitment to the organization. Journal of Occupational Psychology, 63(1), 1-18.

Allen, N. J., \& Meyer, J. P. (1990). Organizational socialization tactics: A longitudinal analysis of links to newcomers' commitment and role orientation. Academy of Management Journal, 33(4), 847-858.

Bauman, C. W., \& Skitka, L. J. (2012). Corporate social responsibility as a source of employee satisfaction. Research in Organizational Behavior, 32, 63-86.

Brammer, S., Millington, A., \& Rayton, B. (2007). The contribution of corporate social responsibility to organizational commitment. The International Journal of Human Resource Management, 18(10), 1701-1719.

Buckley, R., \& Caple, J. (2009). The theory and practice of training. Kogan Publishers.

Carroll, A. B. (1991). The pyramid of corporate social responsibility: Toward the moral management of organizational stakeholders. Business horizons, 34(4), 39-48.

Chew, J., \& Chan, C. C. (2008). Human resource practices, organizational commitment and intention to stay. International journal of manpower.

Ehnert, I., Harry, W., \& Zink, K. J. (2014). Sustainability and HRM. In Sustainability and human resource management (pp. 3-32). Springer, Berlin, Heidelberg.

Eweje, G., \& Bentley, T. (2006). CSR and staff retention in New Zealand companies: A literature review.

Gorusch, R. L. (1983). Factor Analysis (2nd ed.). Hillsdale, NJ: Lawrence E. Associates.

Heathfield, A. (2007). Out of now: The life works of Teaching Hsieh. Thames and Hudson.

Heller, D., Perunovic, W. Q. E., \& Reichman, D. (2009). The future of person-situation integration in the interface between traits and goals: A bottom-up framework. Journal of Research in Personality, 43(2), 171-178.

Hilgert, J. (2012). The future of workplace health and safety as a fundamental human right. Comp. Lab. L. \& Pol'y J., $34,715$. 
Konrad, A. M. (2005). Examining the contours of workplace diversity. In Handbook of workplace diversity (Vol. 1).

Lee, C. H., \& Bruvold, N. T. (2003). Creating value for employees: investment in employee development. The International Journal of Human Resource Management, 14(6), 981-1000.

Lund, D. B. (2003). Organizational culture and job satisfaction. Journal of business \& industrial marketing.

Meyer, M. (2002). Managing Human Resource Development: An Outcomes-based Approach.-. LexisNexis Butterworths.

Pallant, Julie F. (2005). SPSS Survival Manual: a step by step guide to data analysis using SPSS version 12 (Second edition). Open University Press.

Parvin, M. (2011). Factors affecting employee job satisfaction of pharmaceutical sector. Australian Journal of Business and Management Research, 1(9), 113-121.

Patrick, H. A., \& Kumar, V. R. (2012). Managing workplace diversity: Issues and challenges. Sage Open, 2(2), 2158244012444615.

Peterson, D. K. (2004). The relationship between perceptions of corporate citizenship and organizational commitment. Business \& society, 43(3), 296-319.

Peterson, R. A., \& Anand, N. (2004). The production of culture perspective. Annual Review Sociology, 30, $311-334$.

Rettab, B., Brik, A. B., \& Mellahi, K. (2009). A study of management perceptions of the impact of corporate social responsibility on organisational performance in emerging economies: the case of Dubai. Journal of business ethics, 89(3), 371390.

Rhoades, L., \& Eisenberger, R. (2002). Perceived organizational support: a review of the literature. Journal of applied psychology, 87(4), 698.

Shahnawaz, M. G., \& Jafri, M. H. (2009). Psychological capital as predictors of organizational commitment and organizational citizenship behaviour. Journal of the Indian Academy of Applied Psychology, 35(Special Issue), 78-84.

Stockdale, M. S., \& Crosby, F. J. (2004). The psychology and management of workplace diversity. Blackwell Publishing.

Sutherland, V. J., \& Cooper, C. (1990). Psychology \& Health Series 5, Understanding Stress: A Psychological Perspective for Health Professionals. Chapman and Hall, London.

Tsai, M. T., \& Huang, C. C. (2008). The relationship among ethical climate types, facets of job satisfaction, and the three components of organizational commitment: A study of nurses in Taiwan. Journal of Business Ethics, 80(3), 565-581.

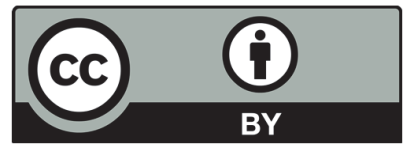

(C) 2020 by the authors; licensee Growing Science, Canada. This is an open access article distributed under the terms and conditions of the Creative Commons Attribution (CC-BY) license (http://creativecommons.org/licenses/by/4.0/). 